\title{
Verb-particle constructions in Cognitive Linguistics perspective: Compositionality behind selected English phrasal verbs
}

\author{
Izabela Jarosz \\ Maria Curie-Skłodowska University, Poland
}

\begin{abstract}
The developments in Cognitive Linguistics have made it possible to uncover multiple meanings of composite structures to the effect that more and more scholars have become interested in the issue of semantic relations in verb-particle constructions. With only a handful of those focusing on both elements of such constructions, many of them have directed their research towards the study of particles exclusively. The current paper aims to advance the study on phrasal verbs by offering a new outlook on their compositional nature. In order to achieve a desired aim, the principle of partial compositionality is adopted here. Hence, apart from focusing on both the verb and the particle, the senses that go beyond those comprising the composite parts receive considerable attention in this study. The phrasal verbs singled out for the purpose of the analysis include: get and take with selected spatialorientational particles.
\end{abstract}

Keywords: compositionality, conceptualization, phrasal verbs, semantic network

\section{Introduction}

Traditional approaches to language considered phrasal verbs $(P V)^{1}$ in terms of arbitrary and unpredictable linguistic units impossible to outline any compositionality (e.g. Celce Murcia and Larsen Freeman 1983). In most cases, PV were analysed with regard to their syntactic structure (Bolinger 1971, or Fraser 1976). Among others, it was Linder (1981) who first looked at PV in Cognitive Linguistics (CL) perspective, applying Langacker's space grammar in their analysis. Together with her followers (Morgan 1997; Hampe 2000; Rudzka-Ostyn 2003; Olson 2013; Mahpeykar and Tyler 2014), it has been evidenced that PV have their non-arbitrary,

1 Generally, in the literature on phrasal verbs, there is a distinction between verb + preposition constructions, e.g. run into, and verb + particle constructions, e.g. put up (cf. Bolinger 1971; Fraser 1976; Celce-Murcia and LarsenFreeman 1983). In this paper, we shall mainly focus on phrasal-verbs being the verb-particle construction type. 
compositional nature organised in a relatively systematic manner. The rules of compositionality and their appliance in PV analysis are, therefore, explained in the current section of this paper.

\subsection{Compositionality in $C L$}

Generally, as Evans and Green (2006: 450) notice, the principle of compositionality requires that the meaning of a complex expression results from the meanings of its parts and the way of their combination. In formal semantics, the meaning has been affected merely by the grammatical structure, this resulting in the claim that the properties of a composite structure can be fully determined by the properties of its component elements and the way of their combination. Still, Sweetser (1999: 129) notices that being "a central fact of language [...] [compositionality] has been given inadequate treatment in formal semantic models." She opposes the view that compositionality is merely the sum of composite elements and argues that it is "the interpretation [which] suggests that a variety of mechanisms may be involved in their semantic composition" (p. 131). Meaning is not just a set of binary features, but a representation that incorporates certain interactions and viewpoints. As Taylor (2002: 589) continues, the whole unit only partially results from the meanings of its component elements.

'.. the interpretation we give to a linguistic expression typically goes well beyond what is actually said [and consequently] the meaning of a complex expression is rarely, if ever, [fully] 'compositional.' That is to say, complex expressions nearly always have a meaning that is more than, or even at variance with, the meaning that can be computed by combining the meanings of the component parts.'

Taylor (2002: 13)

In other words, the meaning of a composite structure does not merely embrace the semantic content of its composite parts, but it also contains senses that are wider or different than those parts. Apart from this, as Taylor (2002: 98) argues, a composite expression incorporates interpretation based on conceptual knowledge that "goes beyond what is actually symbolized in a complex expression." Strictly speaking, although relies on it, a composite unit itself does not contain conceptual knowledge necessary for its interpretation.

Much in similar vein, Langacker (1987: 281) notices that the sense of a composite structure "is experientially distinct from the recognition of the individual components plus instructions for their integration, and it may involve entities and specifications beyond those provided by the components." The elements, therefore, only partially contribute to the meaning of a complex expression. Langacker (1987: 278) explains that "linguistic convention cannot provide a fixed, unitary expression for every conceivable situation that a speaker might wish to describe [as it contains only] a limited inventory of fixed expressions" which code merely some aspects of complex conceptual knowledge and a set of conventional patterns that allow combination of these conceptualizations when necessary." To put it bluntly, in many cases, the speaker might wish to symbolize a complex conceivable situation, but there is no fixed expression that would describe it fully. Hence, s/he puts their conception into smaller, separate and overlapping language chunks that can be reflected in linguistic symbols. This serves to mirror the speaker's intended expression of a conceivable situation. 
For Tyler and Evans (2003: 8), a linguistic form contains the central ${ }^{2}$ meaning while the extended senses can only be reconstructed and, therefore, are not packed into the linguistic form. It is the language user who has to reconstruct the extended senses on the basis of background knowledge. This results in a situation where only those parts of meaning that are necessary to understand a given context are reconstructed.

'... interpretation $[\ldots$ understood as] meaning construction is not simply the result of compositionally adding linguistic items. [...] Utterances [...] provide only minimal prompts for meaning construction. [...] The source of much of the information which is necessary to establish an interpretation is not conventionalized information associated with a lexical item.'

Tyler and Evans (2003: 8)

The aforementioned postulations are in accord with Goldberg's (1995: 13) claim about a construction wherein "something about its form, meaning, or use is not strictly predictable from other aspects of the grammar," or in other words, from the component parts. She argues that "compositionality in a weakened form [means that] the meaning of an expression is the result of integrating the meanings of the lexical items into the meanings of constructions (p. 16) [being] typically associated with a family of closely related senses rather than a single, fixed abstract sense" (p. 31). To put it bluntly, the meaning of a complex structure does not only contain the meanings of its component elements, but also the senses closely related to them.

Additionally, according to Langacker (1987: 448) "the degree to which the value of the whole is predictable from the values of its parts" is a process that can be quite difficult at times. This happens because the element parts are not simply building blocks ${ }^{3}$ that can be assembled and disassembled freely. Apart from the conceptual knowledge that needs to be packed into overlapping language chunks, the influence of one unit upon another during their combination seems to add more complexity to the process of untangling the semantic composition. The latter, known as coercion, is defined by Taylor (2002: 589) as "the phenomenon whereby one unit forces a change in the specification of a unit with which it combines. This amounts to saying that "one unit 'coerces' its neighbour, forcing a change in its specification" (p. 330). Once the coercion occurs, as Taylor (2002: 588) continues, the complex element is likely to evidence the property of bondedness which makes it difficult to identify the component parts of the unit. In other words, "[t]he units become 'bonded' in a relatively unanalysable structure."

In general, as regards compositionality, CL opposes the view that the element parts fully contribute to the meaning of the composite unit. There is also conceptual knowledge that is reconstructed on the basis of our background knowledge. Although the reconstructed part of the meaning cannot be packed into the unit, it typically belongs to the network of closely related senses of the composite structure. Moreover, one composite part might influence its neighbour

2 In this paper, the term central refers to the basic meaning of physical nature while extended is used to mean 'non-basic' and is not strictly physical or spatial. The expressions figurative and metaphorical refer to 'nonphysical' meaning. The term additional sense/meaning is used with reference to the meaning that is not part of the composite elements that form PV.

3 Evans (2007: 14) explains that the term building block metaphor, coined by Langacker, refers to the principle of compositionality in formal linguistics which holds that "the meaning of a complex expression is the result of compositionality adding the meaning of the individual units." 
so that their contributions are not equal. Having the aforementioned postulations in mind, let us now move to the issue of phrasal verbs analysed in CL perspective.

\subsection{Phrasal verbs in $C L$}

Among others, it is Linder (1981) who provides us with the analysis of verb-particle constructions in CL perspective. Using Langacker's framework of space grammar, Linder (1981: 246) gives an account of the relationship between the trajector (TR) and the landmark (LM) in her analysis of PV. Focusing on verb-particle structures with out and up, she claims that PV have both concrete and abstract meanings where each set has a separate, unified network organized in a fixed manner. The main source of meaning for the verb-particle construction is mainly determined by the particle. The study, therefore, focuses on how the central meaning for each particle gives rise to the rest of its extended senses.

Advancing on Linder's study, Morgan (1997) applies the conceptual metaphor theory in analysing English phrasal verbs where "both the verb and the particle [...] contribute semantically to the verb-particle construction" (p. 327). According to Morgan (1997: 355), in constructing phrasal verbs, there are four possibilities for meaning extensions where both the verb and the particle are literal, or both are metaphorical, the verb is metaphorical and the particle is literal, or the verb is literal and the particle is metaphorical. Still, only in the literal sense of both elements there is a common literal source domain for the verb and the particle. In all the other combinations, there are two different source domains. As Morgan (1997: 338) specifies, it is crucial to establish the literal senses of the verb and the particle and then take into account their metaphorical extensions.

Rudzka-Ostyn (2003) explains the compositional meaning of PV in CL perspective, attempting to solve the didactic problems posed by those composite structures. Her approach is presented in the learning materials for EFL students. Rudzka-Ostyn (2003: 9-11) focuses there on a central image schema and the relationship between TR and LM. The motivation behind the extended meanings of English particles is explained on the basis of the conceptual metaphor theory proposed by Lakoff (1987). There is no division into central and extended senses of the particle and not much attention is drawn to the semantic contribution of the verb. What she focuses there on is the same particle combined with different verbs. The main aim is to provide a workbook that meets the criteria of pedagogical grammar ${ }^{4}$ where the semantic gradation from literal to figurative meanings takes its prime.

Tyler and Evans (2003) do not focus on phrasal verbs, but on prepositions that can take part in verb-particle constructions. Tracing the meaning extension through polysemy, they develop the Principled Polysemy Model offering clear principles for analysing semantic networks. Their research on prepositions involves identification of the central meaning from which the other senses are extended systematically. In their approach, the linguistic expression contains only the central meaning while the extended senses are to be reconstructed on the basis of our background knowledge. Therefore, they account for the fact that the meanings of

\footnotetext{
4 As Dirven (2001:18) explains, pedagogical grammar refers to learning materials that contain "the best possible illustration, presentation and gradation of the learning problems in a given area of foreign language learning."
} 
prepositions are derived from human embodied experience and conceptualization of the spatial/physical world.

Olson (2013) investigates the difference between the separable and non-separable transitive PV. Her study is based on the combination of Bolinger's (1971) and Gorlach's (2004) findings adopting Construction Grammar as the theoretical framework. She explains why compatibility with the word order alternation is absent in case of non-separable PV by taking into account specific syntactic and semantic circumstances. Her findings suggest that the lack of word order alternation occurs with the non-separable verb-particle constructions due to the fact that their particles act both as adverbial particles and prepositions.

It is Mahpeykar and Tyler (2014) who suggest taking into account both the verb and the particle in analysing the meaning of verb-particle constructions. In their analysis, they postulate a systematic, consistent account for the semantic behaviour of PV by combining the meaning of the verb with the meaning of the particle through polysemy. Relying on Tyler and Evans (2003) methodology, Mahpeykar and Tyler (2014) provide us with the criteria for identifying the senses in relation to the element parts as well as the whole composite unit.

Luo (2019) offers a deep investigation of PV, focusing on the conceptual content of PV schemas, the particle placement with transitive PV and the idiomaticity of PV. In the first case, much attention is devoted to the role of the particle component classifying particle constructions into directional, resultative and aspectual groups. It is argued that the particle placement of transitive particle verbs is the outcome of profiling two construals of one conceptual content. The idiomaticity of particle verbs is said to result from the semantic extension of the particle component, the verb component, both, the subject or object taken by the PV, particle-verb schemas, or the level of the full particle verb.

Luo (2019: 35) claims that Mahpeykar and Tyler's (2014) analysis is verb-centred in the sense that it is the verb that holds a central position in structuring an integrated conceptual scene and in this respect does not differ from Linder's (1981) or Morgan's (1997) studies. However, as it will be outlined in our analysis, Mahpeykar and Tyler's (2014) study might serve as a good basis for building a network of sense relations of a given PV which will evidence that both components are equally important. At this point, let us give a closer look at Mahpeykar and Tyler's (2014) methodology. As regards the coding scheme for distinct and central meanings of particles alone, they rely on Tyler and Evans (2003) typology. Then, they use this model to develop the typology of verbal meanings as well as the meanings of the whole verb particle constructions.

The coding scheme for determining the distinct senses of a particle, taken from Tyler and Evans (2003: 42-43), is built on the basis of the following criteria:

- the meaning of the extended sense must be non-spatial/non-physical or TR-LM configuration different than in the central sense;

- the extended sense cannot be inferred from another sense and the context in which that sense occurs.

For identifying the central sense, the following conditions need to be taken into consideration (Tyler and Evans 2003: 47):

- the earliest attested etymological meaning; 
- the predominance of the sense in the polysemy network;

- the use in composite forms;

- the relations to other spatial particles;

- grammatical predictions.

When it comes to the coding scheme for the verbs as developed by Mahpeykar and Tyler (2014), it is greatly based on Tyler and Evans (2003) methodology for analysing prepositions. The criteria adopted by Mahpeykar and Tyler (2014: 9-10) include:

- the central sense is the earliest attested sense in etymological dictionary and needs to be strictly physical/spatial in meaning;

- the extended meanings can be traced back to the central sense using CL principles for meaning extension;

- the distinct sense must contain additional meaning not apparent in other proposed senses;

- the extended sense cannot be strictly physical/spatial in meaning;

- extended sense prompts for a different spatial scene.

Having analysed both elements of a composite structure separately, Mahpeykar and Tyler (2014: 11) study the whole construction. They use the coding scheme analogous to the one adopted for establishing the central and extended senses of the verbs. Then, they present the original sense of a composite structure and its distinct meanings, explaining which sense of the verb and which sense of the particle takes part in each PV combination.

The study by Mahpeykar and Tyler (2014) offers a very precise tool for PV analysis. It includes a thorough examination component parts of PV separately as well as the PV as a whole. Still, their presentation of the composite structure focuses on outlining the central and extended senses of PV without stressing internal sense relations within the semantic network. It can be deduced from their study that the extended senses of a given PV do not necessarily come from the core meaning of this PV, ${ }^{5}$ as it is in the case of single verbs or particles. Therefore, it should be highlighted that the semantic network of a PV would be totally different from the pattern where the extended senses are inherited from the central one. Apart from that, it has been observed that the extended senses contain meanings that are not parts of the meanings selected for their combinations. ${ }^{6}$ Hence, when analysing PV, we need to take into consideration not only central and extended senses of the whole composite structure but also the central and extended senses of its elements. For this reason, it is suggested to complete the methodology offered by Mahpeykar and Tyler (2014) and highlight direct and indirect relations between the senses in the network as well as the additional meaning not being inherited from the component elements straightforwardly.

\footnotetext{
5 For example, the central sense of get up consists of the central particle and the extended (not central) verb while its extended sense 'become upright' consists of the extended verb and the extended particle. The semantic network, then, would not follow the pattern in which the core meaning directly gives rise to its extended senses.

6 For instance, in get out which has three extended senses, the meaning 'not in situ' also contains the meaning 'change of the state' while 'become known' contains the meaning 'sb tries to hide it but unsuccessfully.'
} 


\section{Current research methodology}

In our analysis, we shall focus on the relations between the senses, and the source of additional meaning not being part of the composite elements of PV. In order to achieve desired results, we suggest the establishment of the semantic networks for the selected constructions, presenting all the possible meanings of both composite elements. The units chosen for the current study include four PV previously analysed by Mahpeykar and Tyler (2014): get up, take up, get out, and take out. We use the coding scheme for the verbs and the particles as proposed by Mahpeykar and Tyler (2014). For the verb particle constructions, we use a more detailed process than the one offered by them, additionally taking into account the principle of compositionality as explained by Goldberg (1995) and the phenomenon of coercion as described by Langacker (1987) (see Subsection 1.1).

Our hypothesis, therefore, includes the following assumptions:

- each PV has an additional meaning not being inherited from its composite parts directly, but related to them;

- in each verb-particle construction there is a dominant element that influences the meaning.

The method adopted to prove the above hypothesis includes the following steps:

- to reconstruct the complete sense networks of PV get plus up, take plus up, get plus out, take plus out, including all the senses of the verb and the particle, also those not taking part in meaning construction of the PV in question;

- to reanalyse and reconstruct the meanings of the selected PV as offered by Mahpeykar and Tyler (2014), taking into account also the senses from Cambridge English Dictionary (CD) and Macmillan Dictionary of Phrasal Verbs (MDPV), ${ }^{7}$ in order to trace the additional sense and the dominant element;

- to compare the additional meaning and the dominant element with all the extended meanings of verbs and particles in a network.

The subsequent Section outlines how the above methodology is applied to the analysis of the selected PV.

\footnotetext{
The senses provided by Mahpeykar and Tyler (2014) are based on Online Etymology Dictionary combined with the Corpus of Contemporary American English, WordNet and Cambridge Learner's Dictionary. It has been decided to expand the analysis of the senses, referring to CD and MDPV due to the fact that the former is a set of corpus-informed dictionaries including the Cambridge Advanced Learner's Dictionary, the Cambridge Academic Content Dictionary, the Cambridge Business English Dictionary as well as Essential American English Dictionary, Essential British English Dictionary, and Learner's Dictionary while the latter is a contemporary dictionary solely devoted to phrasal verbs which contains special entries devoted to most common particles and their contribution to the meaning of PV.
} 


\section{Analysis}

With regard to the meanings of the particles and the verbs alone, the present study relies on Mahpeykar and Tyler's (2014) analysis. As regards the particles, the central up 'TR at the top of the LM' has four extended senses: 'more,' 'completion,' 'improvement,' 'activity.' The central out 'TR exterior to the LM,' on the other hand, contains nine distinct meanings: 'completion,' 'no more,' 'not in situ,' 'visibility,' 'knowing,' 'exclusion,' 'lack of visibility,' 'distribution,' 'reflexibility.' When it comes to the verbs, the central get 'obtain' has three extended senses: 'move,' 'change of the state,' 'achieve sth with effort.' The central take 'get hold and remove' has six distinct meanings that include: 'occupy/extended use,' 'accept,' 'convey 8 go and be responsible for,' 'need,' 'understand,' 'do sth to achieve results.' Instead of presenting central and extended meanings of the verbs and the particles in the linear form, it has been decided to draw networks of sense relations for up, out, get, and take.

The composite structure of $\mathrm{PV}$ requires the verb and the particle as its component elements. Hence, in our study, a network of get has been combined with a network of up (Subsection 3.1), then, a network of get with a network of out (Subsection 3.2), a network of take with a network of up (Subsection 3.3), and a network of take with a network of out (Subsection 3.4). On the basis of Mahpeykar and Tyler's (2014) analysis, additionally enriched by taking into consideration the meanings from CD and MDPV, one of the senses of the verb has been linked with one of the senses of the particle to form the central and the extended senses of a given PV. ${ }^{9}$ In comparison with the single verb or particle networks, two basic differences, invisible in Mahpeykar and Tyler's (2014) study, should be mentioned. First, the central sense of each analysed PV consists of the central sense of the particle and either the central meaning of the verb or its extended sense. Second, the extended senses of each PV are not necessarily composed of the extended meanings of both the verb and the particle. Its composite senses might also include the combination of the central meaning of the verb and the extended meaning of the particle, or the extended meaning of the verb and the central meaning of the particle.

The networks of the selected PV below illustrate which sense of the verb and which sense of the particle combine to form the composite structure. The red colour of the font refers to the central sense of the verb and the particle. Their extended meanings are marked with single, black arrows. The double, bold arrows refer to the elements comprising PV. The double, bold, red arrow marks the central sense of the PV while the double, bold, blue arrow refers to the extended sense of PV. The single, blue arrow refers to the additional meaning not being inherited from the composite elements of the PV.

\footnotetext{
8 The basic meaning of convey here is 'to take or carry somebody or something to a particular place' and in this respect is compatible with 'go and be responsible for.' Its extended version 'to express something so that it is understood by other people' (literally 'to carry some new idea to the minds of other people') will also be used in our analysis. Hence, when enumerating the meanings of take, we feel it necessary to insert 'convey' along with 'go and be responsible for.'

9 Our judgments have been discussed with two external raters: an Assistant Professor from the Department of English Studies (a non-native speaker) and a teacher of English who is also a native speaker of this language.
} 


\subsection{Get up}

The central sense of get up is composed of the extended verb get 'move' an the central particle up 'TR at the top pf the LM.' The meaning refers to 'an entity moving or being caused to move from a lower position to a higher position.' The meaning of the resultant PV is physical and this aspect has apparently been coerced by the physical particle.

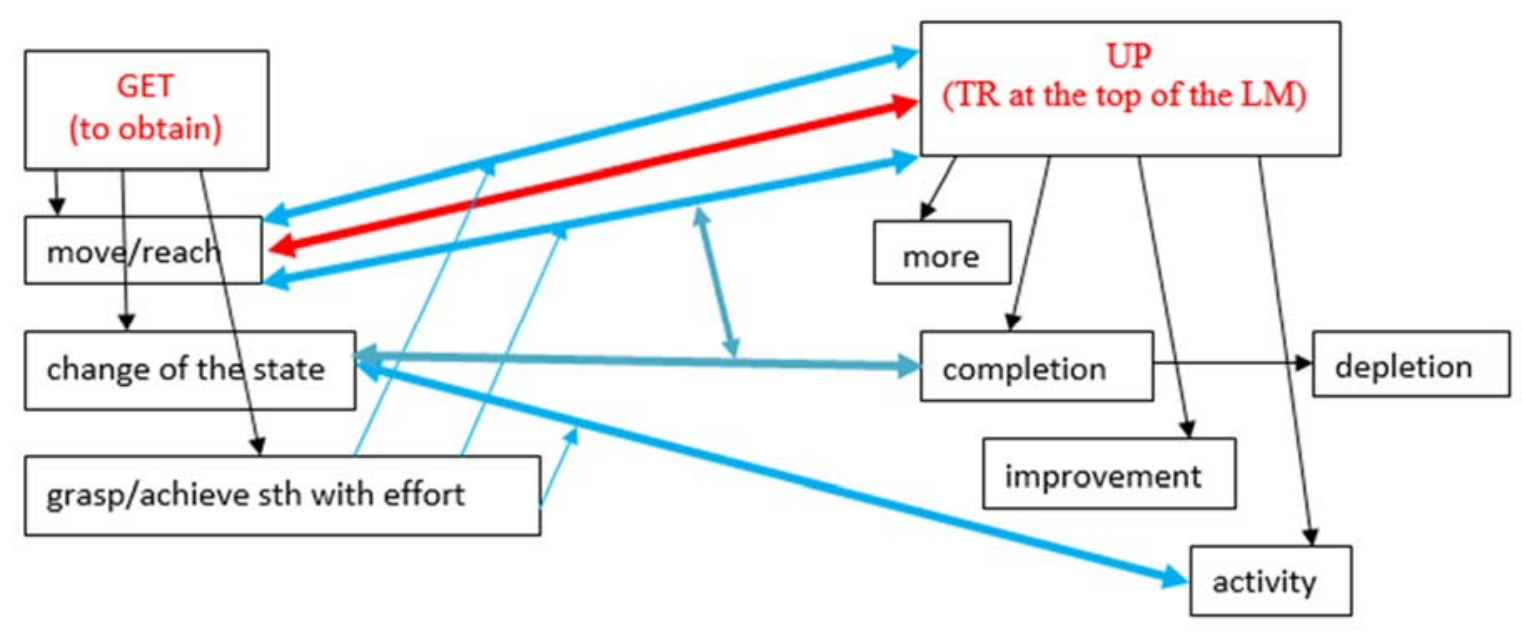

Figure 1: Semantic network for get up

The extended senses of get up include:

(1) 'become upright' - composed of the extended get 'move' and the central up 'TR at the top of the LM.' The meaning is physical apparently due to the influence of the physical particle. Analysing this sense in different contexts, we could notice that in each case there is some additional meaning involving doing this action with some effort or challenge, e.g. I tried to get up but he leaned over me; After the fall, he got up and dusted himself off (CD) or Dr Blake [...] doesn't want you to get up yet = 'you are too weak to stand up' (COCA). In all the cases, returning to the upright position requires some physical effort. This evidences that apart from being composed from the meanings of its composite parts, this $\mathrm{PV}$ also contains the extended meaning of get 'achieve sth with effort' and in this respect the verb plays the dominant role.

(2) 'awake and move out of bed' - composed of the extended get 'move' and the central up 'TR at the top of LM.' At first glance, it is physical since it involves 'physical movement of moving upwards' influenced by the particle. Additional meaning including get 'achieve sth with effort' can frequently be visible here. For example, It is so hard getting the kids up on schooldays = 'persuading kids to get out of bed early requires a lot of determination;' She listened to the radio for half an hour before getting up and going to work = 'it was difficult for her to move out of bed and start working, she preferred relaxation' (CD) or Will you get me up at six tomorrow? = 'I need someone to help me because I am a heavy sleeper' (MDPV); or I had to get up at five in the morning because there was so much to do = 'I got up so early only because I had many duties, otherwise I would stay in bed' (COCA). However, when talking about awaking, the physical nature of meaning is not so straightforward. While moving out of bed to become in the upright position involves 
physical movement, awakening does not necessarily entails leaving bed. We may awake and stay in bed. Here, it is rather change of the state from unconscious to conscious and the end of sleeping that matters. Therefore, we would say that in this context 'awake' part of the meaning is composed of extended get 'change of the state' and extended up 'completion.' Unlike 'moving out of bed to the upright position,' there is no additional physical effort in this part of meaning. Hence, the sense of the PV is composed of get 'change of the state' and up 'completion' plus get 'move' and up 'TR at the top of LM.' This results in the PV being non-physical to a certain degree. The particle is dominant as it coerces physical nature of the meaning. The physical sense 'moving to the upright position' is influenced by 'TR at the top of the LM' while the non-physical meaning 'awake' is forced by 'non-physical completion' and 'change of the state.' The dominant role of the verb can also be marked by its additional meanings 'achieve sth with effort' and 'change of the state' that take part in the composed PV.

(3) 'organise an event' - composed of the extended get 'change of the state' and the extended up 'activity.' The additional meaning which is part of a different sense of get involves 'achieving sth with effort.' ${ }^{10}$ In this perspective, the verb is dominant as it adds more meaning to the composed PV. For example, We managed to get a team up to play them at football = 'we put some effort and succeded in persuading the team to play;' or Local people got up a petition against the factory closure = 'they had to ask or persuade a large number of people to sign the document in order to bring back the factory to work' (MDPV); Get up, get into it and get involved = 'organising an activity requires an effort of becoming interested and involved in it' (COCA) or He's getting up a small group to go carol-singing for charity = 'organising a group of people requires a lot of arrangements and preparations' (CD). The meaning of PV is non-physical and in this respect it is by the non-physical verb and particle.

\subsection{Get out}

The central sense of get out is composed of the extended sense of get 'move' and the central sense of out 'TR exterior to the LM.' The meaning refers to 'an entity moving from the interior to the exterior region.' The physical particle influences the physical meaning of this PV. For instance, I'll get out when you stop at the traffic lights (CD) = 'I'll leave your car,' or They got the injured people out as quickly as they could (MDPV) = 'they removed the injured people from the place.'

Get out has three distinct senses:

(4) 'socialize'11 - composed of the extended get 'move' and the extended out 'not in situ.' The meaning involves 'leaving a typical place of habitation for a social activity.' The additional

10 The particle sense of 'completion' could fit this case, as well. However, completion as endpoint is already coded by the meaning of 'achieve' here ( $c f$. achieve in $\mathrm{CD}$ ).

${ }^{11}$ Mahpeykar and Tyler (2014: 26) use the meaning 'not in situ', however, it is also the meaning of out and might cause some ambiguity here. We would say that it is 'socialising outside home' rather than simply 'leaving the place of usual habitation' that fits better in this context. 
sense refers to 'the change of the state' being the part of a different extended sense of get. Here, the change is from routine or boredom to entertainment or meeting other people in public. ${ }^{12}$ For instance, We don't get out much these days (MDPV); People should not get out there and start dating until they have that in check (COCA); or We don't get out much since we have children (CD). Since the verb adds more meaning to the composed PV, it might be said that it is dominant in this respect. In the aforementioned examples, the PV does not imply that these people do not leave their houses at all, but do not do it to socialize with others. The meaning of the PV is, therefore, non-physical and influenced by both the extended verb and the extended particle.

(5) 'become known' - composed of the extended get 'change of the state' and the extended out 'knowing. ${ }^{13}$ The additional meaning involves 'some effort to hide the secret' and is part of the extended get in the sense 'achieve sth with effort.' Unlike out alone which refers to 'information made public' or 'information no longer kept secret,' e.g. You can't hide your gambling - the secret is out (CD), in get out the element of 'attempting to keep sth secret' is emphasised. The entry is explained as follows: "if news or information gets out, people hear about it although someone is trying to keep it secret," e.g. I don't want to get it out that I'm leaving (CD) ${ }^{14}$ or I lower my blood pressure after reading the news is to get out (COCA). The meaning of the PV is of non-physical nature being influenced by the extended verb and particle. The dominant role of the verb is also marked by the additional meaning taking part in the composed PV.

(6) 'become available' - composed of the extended meaning of get 'change of the state' and the extended meaning of out 'visibility/ accessibility.' Additional sense includes 'achieving sth with effort' which is the part of another extended meaning of get. In the examples I finally got my invitations out; The company got the report out on time (CD); Put someone in jail, and they can't come up with the money to get out (COCA) or If you can get your book out in reasonable time, I can see it being a real winner (MDPV), it is clearly visible that the sense involves 'some effort to achieve a desired result.' As regards the amount of meaning, it is the verb that dominates here. As regards its non-physical nature, it is influenced both by the verb and the particle.

${ }_{12}$ Mahpeykar and Tyler (2014: 13) indeed mention that the change of location entails the change of the environment and physical or emotional state, proving different examples, but they do not seem to highlight this meaning in the PV in question. Similarly, the contextualized version of get up referring to 'encouraging voters to leave their work or home in order to vote' apparently contains an additional element of 'expressing an opinion as a member of a group,' hence, involves change. Still, this extra sense is not mentioned by the authors.

13 Although in cognitive terms the relation between seeing and knowing is recurrent, the present analysis distinguishes between knowing as a mental operation and seeing as something involuntary that is happening without any conscious effort; hence visibility is related to accessibility more than to knowing here.

${ }^{14}$ Nonetheless, MDPV does not highlight the fact that the secret is attempted to be hidden and is made public involuntary. The dictionary explains the entry as follows: "If something secret gets out, a lot of people find out about it." 


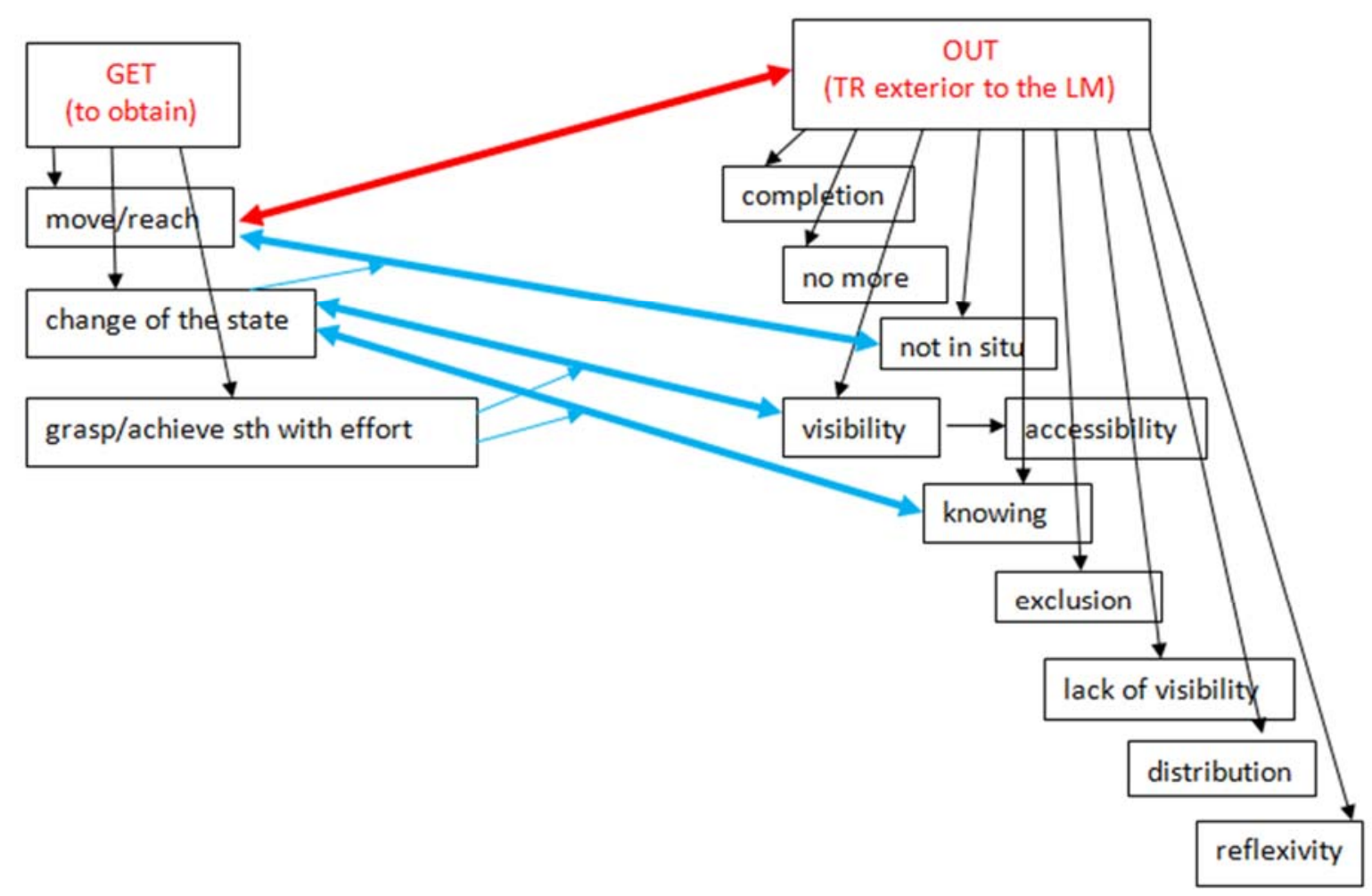

Figure 2: Semantic network for get out

\subsection{Take up}

The central sense of take up includes the central take 'get hold and remove' and the central up 'TR at the top of the LM,' and refers to 'an entity in the hand which has been moved from a lower position to a higher one.' For instance, Who will take up Cap's shield? (COCA). The meaning is rarely used. The sense physical sense of PV is apparently influenced by the physical particle.

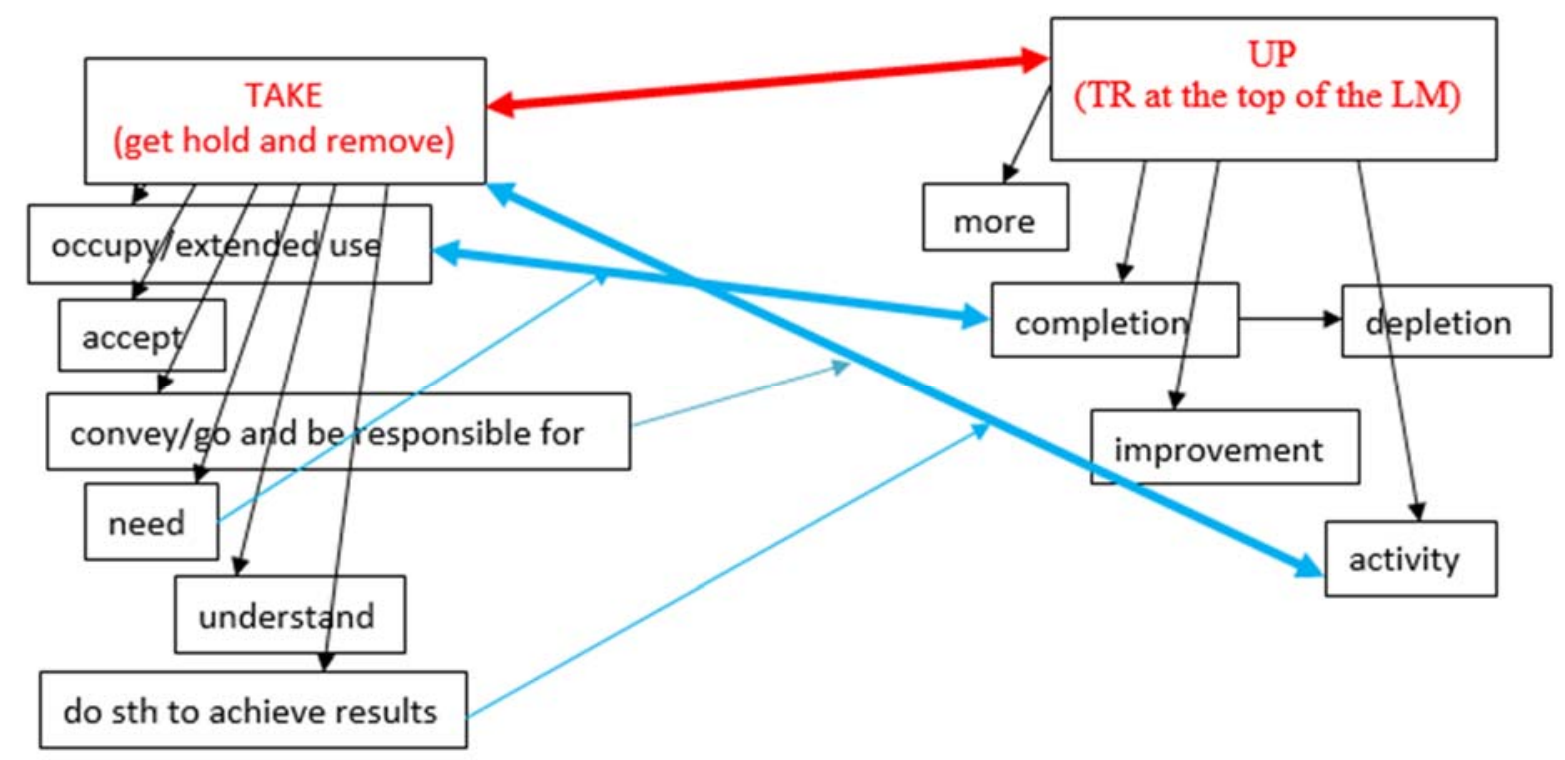

Figure 3: Semantic network for take up 
The extended meanings of take up include:

(7) 'become engaged with an activity/ idea' - composed of the central take 'get hold and remove' and the extended $u p$ 'activity.' Two additional meanings taken from the extended take 'do sth to achieve results/grasp' ${ }^{15}$ and 'convey/go and be responsible for' can also be visible in this sense. For instance, Chris has taken up jogging = 'became responsible for and engaged in this activity to keep fit or lose weight;' I took up smoking when I was eighteen $=$ 'on reaching the adulthood I became responsible for my actions and started smoking to feel relaxation;' She fell silent, and her brother took up the story = 'felt responsible to substitute for his sister and became engaged with finishing the story to make others hear the ending' (MDPH) He will step down from the Congress to take up his new position (COCA) or He's taken up the position of a supervisor = 'started a new job to climb the carrier ladder and became responsible for certain duties;' A leading law firm took up his case = 'became responsible for the case and dealt with it as to win it in the court' (CD). In the aforementioned contexts, the meaning 'convey' as explained in note 7 points to the idea of 'newness' that needs to be expressed so that it gets realised or understood (realising someone starting a new activity such as jogging or smoking, another person continuing the story, a new supervisor or a law firm). In all the cases, the speaker realises that something new has happened. The presence of the additional meanings make the verb dominant in composing the structure. Its non-physical nature is by contrast coerced by the particle.

(8) 'occupy space or time' - composed of the extended take 'occupy/extended use' and the extended up 'more' together with up 'completion' which adds some emphasis. In this sense TR uses some parts of the LM more than is needed, e.g. The rider was judged for taking up two seats; Too much of this report is taken up with out-of-date numbers (CD). The 'more' sense highlights the fact that occupying exceeds the norm while the 'completion' sense highlights the fact that it is the endpoint that brings the negative results. In certain contexts of this sense, it can be noticed that the additional meaning connected with the extended take 'need' is apparently visible, e.g. This one comes to us via the dreams and prophecies that take up large sections of the books (COCA) = 'they occupy many pages of the book but are necessary to exhaust the topic;' or These files take up a lot of disk space = 'although it is not desirable, they need to occupy so much disk space;' I'll try not to take up too much of your time = 'although I realise you do not have time, I need to talk to you' (MDPV). The PV is non-physical and the meaning is negative, in general. The verb is dominant here as it adds some extra meaning to the composite structure. The non-physical nature of the PV is influenced by both the verb and the particle.

\footnotetext{
15 Arguably, it can be said that anything people do implies some purpose and result and on the grounds of that exclude the sense from our analysis. However, the meaning is to emphasise the fact of achieving results in certain contexts rather than outlining that it exist only in some situations.
} 


\subsection{Take out}

The central meaning of PV take out consists of the central take 'get hold and remove' and the central out 'TR exterior to the LM'. The sense refers to 'a human hand removing an entity from a container, LM is usually covert'. The instances include: Henry took out his wallet (MDPV) = 'he got the wallet from his pocket' or I took out some money for the weekend (CD) = 'I got money from the ATM.' ${ }^{\prime 16}$

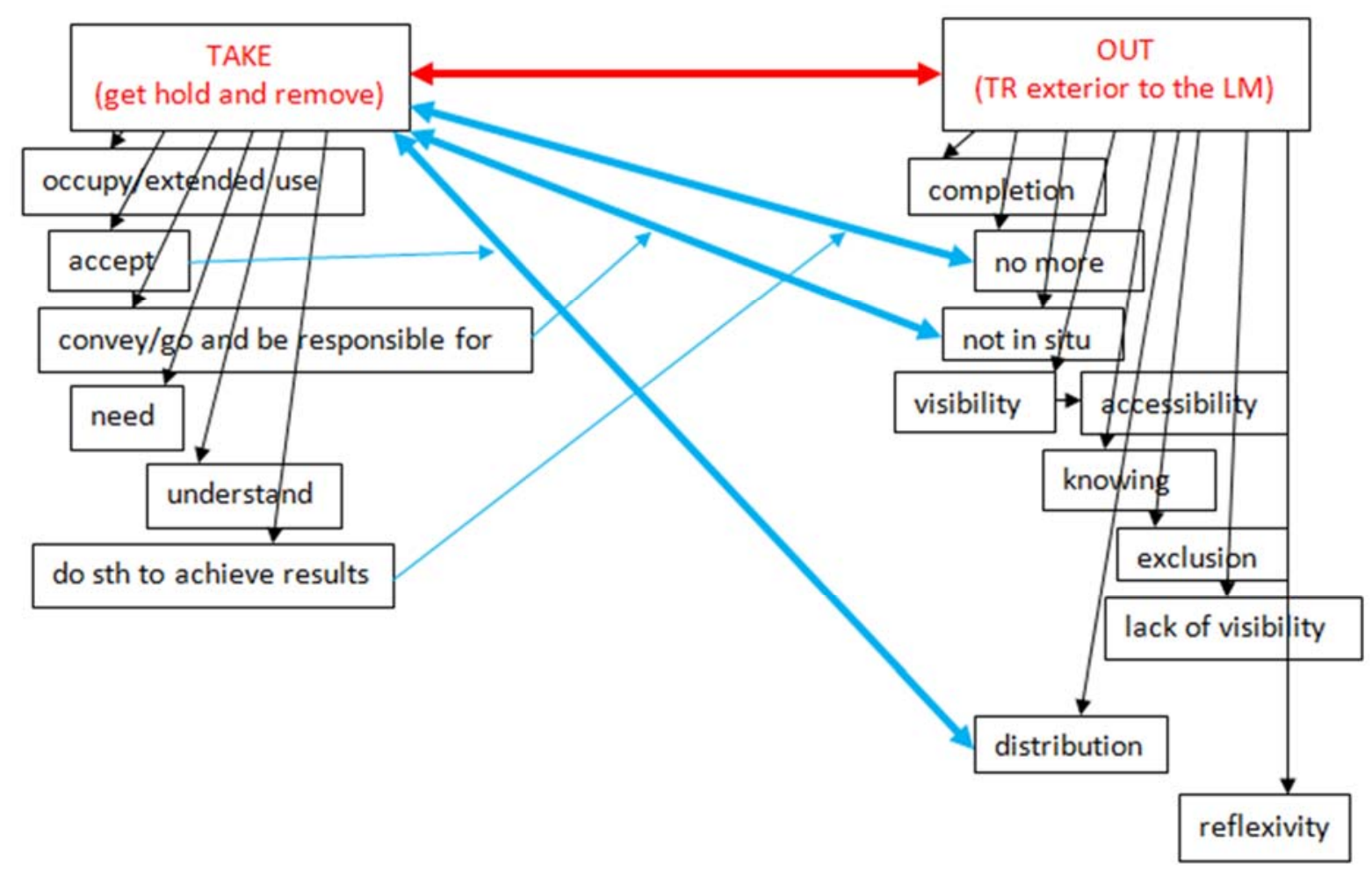

Figure 4: Semantic network for take out

The extended senses of take out include:

(9) 'obtain a legal arrangement from an institution' - composed of the central take 'get hold and remove' and the extended out 'distribute.' Its non-physical meaning is influenced the particle. It involves 'agreeing on certain conditions in order to receive a bank loan with the aim of allotting sums of money to necessary things.' For example, They took a loan out to pay for their wedding (MDPV) or He had to take out a loan to pay his taxes (CD). In both cases, the money is removed from the bank in large amount and then divided into smaller amounts to pay for different aspects of the wedding or different taxes. Another meaning can be 'signing a contract.' For instance, I'll take out extra insurance on Dahlia House (COCA); or When you take out an insurance policy, read the small print (MDPV) $=$ 'the contract involves paying amounts of money on a monthly basis in exchange for getting a financial help in case of some misadventure.' In all the aforementioned instances,

16 However, 'getting money from a bank account' instead of an ATM is not physical in meaning as a bank account cannot be qualified as a literal container. Hence, this sense refers to the extended take out and can be defined as 'a monetary transaction being a legal arrangement.' 
the additional meaning 'accept/agree' which belongs to take not being part of the composite elements forming this PV is clearly visible. In this respect, it is the verb that is dominant in composing the meaning of PV.

(10) 'destroy an entity' - composed of the central take 'get hold and remove' and extended out 'no more.' Its additional meaning includes 'doing sth to achieve results' and is part of the extended get that is not included in the composite parts of this PV. For instance, They call for a comprehensive strategy to take out Assad's air force (COCA); The soldiers said that they were trying to take out the snipers (CD); The night bombing raid took out the bridge (MDPV) or They hire someone to take him out $(\mathrm{MDFV})=$ 'the contract between two parties involves paying someone in exchange of killing another person. ${ }^{17}$ The nature of meaning here is non-physical as it is inherited for the extended particle. The verb is dominant in the sense that it adds some extra meaning to the composite structure.

(11) 'invite sb for a social meeting' ${ }^{18}$ consists of the central meaning of take 'get hold and remove' and the extended meaning of out 'not in situ.' The sense refers to 'socialising with another person or people by going with them to an establishment or an activity outside the home and pay for everything.' The additional meaning comprises the extended sense of take 'convey/go with and be responsible for.' For instance, Can I take you out some time? (MDPV) = 'Can I invite you somewhere where we can entertain/socialize and I'll pay for everything;' I was just the kid sister, the one he used to take out for a hamburger and Coke (COCA) = 'he used to take the responsibility over his sister and pay for her meal;' or Our boss took us out for drinks (CD) = 'our boss wished to socialize with us so s/he invited us to the pub and paid for our drinks.' This sense is non-physical and dominated by the particle in this respect. When it comes to the amount of the meaning, it is the verb that mostly contributes in composing the PV.

Having analysed the meanings of the selected PV in multiple contexts and in relation to their semantic networks, some interesting observations can be noticed. First, in the case of the extended senses of $\mathrm{PV}$, there is some additional meaning being part of the verb's extended meaning that is not a composite element of the construction. In this perspective, the verb is the dominant element of the PV. Second, the central meaning of a PV does not contain additional sense. Here, there is no coercion on the part of the verb. However, in most cases, the physical nature of meaning is correlated with the particle. Hence, we might state that it is the particle that plays a dominant role in composing PV.

\footnotetext{
17 It might seem that take out meaning 'to hire sb to kill' could be analysed in terms of 'signing a contract between the parties' with the additional meaning 'accept/agree' added. Still, in the latter, the sense 'contract' is apparently coded by 'hire' while 'kill sb' refers to 'the act of destroying sb.'

18 The meaning provided by Mahpeykar and Tyler (2014) is described as 'having a date' and refers to 'accompanying someone to an establishment or activity outside the home.' However, the contextual analysis of the selected dictionaries shows that the meaning apparently refers to 'inviting someone to a restaurant, cinema, etc. for a social meeting/entertainment.' A date implies 'a social meeting planned before it happens, especially one between two people who have or might have a romantic relationship' (CD) while the analysed examples indicate that it is not necessarily a couple that can go together somewhere. What is also important in this meaning is the fact that a person who invites others usually pays for everything.
} 
Third, when the central sense of the particle comprises the composite element, the resultant PV is always of physical nature. Fourth, for the composite unit to be of non-physical nature, the extended sense of the particle is necessary to participate in the meaning combination.

\section{Conclusion}

In this study, the compositional nature of PV has been examined. We have analysed four PV previously studied by Mahpeykar and Tyler (2014) with the aim to present further development of their methodology. The results of our research have evidenced that PV display some systematicity not only with regard to the semantic combination of their component verb and particle, but also due to the additional meaning going beyond those elements. It has been outlined that the additional meaning should be searched for among the other senses of the verb. In this respect, it is the verb that plays the dominant role in the PV formation. Additionally, the correlation of PV with the literal or figurative meaning of the particle has been detected, providing a relatively strong evidence for the dominant nature of the particle in this area. Generally, it can be concluded that a PV is a combination of one sense of the verb and one sense of the particle, wherein it is the verb that adds extra meaning to the unit and the particle that determines its metaphorical nature.

Naturally, the investigation of four examples of PV has not exhausted the topic. Further research requires the analysis of more examples. The method can also be applied to other composite structures, such as idioms or compound nouns. The study has also potential implications for designing learning materials in the area of pedagogical grammar.

\section{References}

Bolinger, D. 1971. The phrasal verb in English. Cambridge: Harvard University Press.

$\mathrm{CD}=$ Cambridge English Dictionary [online]. https://dictionary.cambridge.org/ [retrieved ${ }^{\text {st }}$ April 2019].

Celce-Murcia, M., and D. Larsen-Freeman. 1983. The grammar book: an ESL/EFL teacher's course. USA: Heinle and Heinle Publishers.

COCA $=$ Corpus of Contemporary American English. https://www.english-corpora.org/coca/ [retrieved $10^{\text {th }}$ November 2019].

Dirven, R. 2001. English phrasal verbs: Theory and didactic application. In M. Putz, S. Niemeier, and R. Dirven (eds.), Applied Cognitive Linguistics, vol. II: Language Pedagogy, 3-28. Berlin/New York: Mouton de Gruyter. Evans, V. 2007. A glossary of Cognitive Linguistics. Edinburgh: Edinburgh University Press.

Evans, V., and M. Green. 2006. Cognitive Linguistics: An introduction. Edinburgh: Edinburgh University Press.

Fraser, B. 1976. The verb-particle combination in English. New York: Academic Press.

Goldberg, A. 1995. Constructions: A Construction Grammar approach to argument structure. Chicago: University of Chicago Press.

Hampe, B. 2000. Facing up to the meaning of 'face up to': A cognitive semantico-pragmatic analysis of an English verb-particle construction. In A. Foolen, and F. van der Leek (eds.), Constructions in Cognitive Linguistics: Selected papers from the Fifth International Cognitive Linguistics Conference, Amsterdam 1997, 81-101. Amsterdam: John Benjamins.

Lakoff, G., and M. Johnson. 1980. Metaphors we live by. Chicago/ London: University of Chicago Press.

Langacker, R. W. 1987. Foundations of Cognitive Grammar, vol. I: Theoretical prerequisites. Stanford: Stanford University Press. 
Linder, S. 1981. A Lexico-semantic Analysis of English Verb-particle Constructions with UP and OUT. Ph.D. diss., San Diego, University of California.

Luo, H. 2019. Particle verbs in English: a cognitive linguistic perspective. Singapore: Springer.

Mahpeykar, N., and A. Tyler. 2014. A principled cognitive linguistics account of English phrasal verbs with up and out. Language and Cognition 7(01): 1-35, (online version).

MDPV = Macmillan Dictionary of Phrasal Verbs. (2010). Oxford: Macmillan Publishers.

Morgan, P. S. 1997. Figuring out figure out: Metaphor and the semantics of the English verb-particle construction. Cognitive Linguistics 8: 327-357.

Olson, A. 2013. Constructions and Result: English phrasal verbs as analysed in Construction Grammar. Trinity Western University: unpublished MA thesis.

Rudzka-Ostyn, B. 2003. Word power: Phrasal verbs and compounds (a cognitive approach). Berlin / New York: Mouton de Gruyter.

Sweetser, E. 1999. Compositionality and blending: Semantic composition in a cognitive realistic framework. In T. Jansen, and G. Redeker (eds.), Cognitive Linguistics: Foundations, scope, and methodology, 129-162. Berlin: Mouton de Gruyter.

Taylor, J. R. 2002. Cognitive Grammar. Oxford: Oxford University Press.

Tyler, A., and V. Evans. 2003. The semantics of English prepositions: spatial scenes, embodied meaning and cognition. Cambridge: Cambridge University Press. 